\title{
Engaging Citizens: A Cross Cultural Comparison of Youth Definitions of Engaged Citizenship
}

\author{
Elizabeth M. Goering \\ Department of Communication Studies, Indiana University Purdue University Indianapolis, Indianapolis, 46202, Indiana, United States \\ *Corresponding Author: bgoering@iupui.edu
}

Copyright (C) 2013 Horizon Research Publishing All rights reserved.

\begin{abstract}
In recent years, citizenship, particularly what it means to be an engaged and active citizen, has received considerable attention from researchers and theorists in the field of education. This burgeoning interest is not surprising, given that in most societies educational institutions have been accorded primary responsibility for educating young people to become good citizens. As the debate over what it means to be an active citizen continues, and as educators continue to seek ways to foster civic engagement, it is critical to solicit and include the perspectives of young people. In addition, it is important for researchers to explore the ways in which conceptualizations of citizenship might vary across diverse cultures. Through thematic content analysis of narratives of engaged citizenship generated by young people in Germany and the United States, this paper examines cultural differences in the communicative construction of what it means to be an engaged citizen and explores the implications of those differences for higher education.
\end{abstract}

Keywords Engaged Citizenship, Service Learning, Narrative Analysis, Active Citizenship, Civic Engagement

\section{Introduction}

In recent years, citizenship, particularly what it means to be an engaged and active citizen, has received considerable attention from researchers and theorists in a variety of disciplines. This burgeoning interest is perhaps not surprising, given the link that has been established between engaged citizenship and a thriving democracy. The foreword to Civic Responsibility[1] reminds us that "the sustainability of a democracy depends on its citizens' possession of knowledge, judgment, skill, and willingness to engage." Nunn[2] concurs, arguing, "The health of our democracy is measured by many things, but no dimension is more important than an engaged citizenry."

Not surprisingly, the field of education has played a significant role in the ongoing debate about citizenship. After all, in most societies, educational institutions have been accorded primary responsibility for preparing young people to become good citizens. As the debate over what it means to be an active citizen continues, and as educators continue to seek ways to foster engagement in citizens, it is critical to solicit and include the perspectives of young people. In addition, it is important for researchers to explore the ways in which conceptualizations of citizenship might vary across diverse cultures. This paper seeks to further understanding of both of these issues through an analysis of narratives of engaged citizenship produced by young people in two countries, the United States and Germany.

Because this study focuses primarily on narratives, I will begin this essay with a story of my own. The University at which I am employed, Indiana University Purdue University Indianapolis (IUPUI), has placed considerable emphasis on civic engagement, on synthesizing the activities of engaged citizenry with learning. In fact, civic engagement has become an integral part of the culture of IUPUI. It is embedded in the stated mission of the university and written into the institution's strategic plans. I, too, have been active in civic engagement, spear-heading efforts to integrate service learning into the curriculum of our department and regularly involving my students in service-learning activities. Students in the Department of Communication Studies at IUPUI routinely learn about communication theories and principles by "practicing them" in community organizations, such as local food banks, theaters, and public schools.

One semester a few years back, I was teaching the introductory, Gateway class for students exploring communication studies as a major. As part of the civic engagement component of the class, the students spent an evening volunteering at a local food bank. A German colleague just happened to be visiting Indianapolis while on a sabbatical leave, so I invited her to accompany the class on their service-learning trip. We spent three hours at the food bank, filling "back sacks" for needy students. In Indiana, 1 in 4 children live in families that are at or below the federal poverty level, and the back sack program ensures that these children will have something to eat over the weekend. After the students had gone home, I asked our German visitor for her impressions of the experience. She commented 
positively about her interaction with the American students. However, after a brief silence, she added, "But isn't it hegemonic to marshal all these students to take care of a problem that your government really should be taking care of?"

Initially my German colleague's comment took me aback. How could she not be impressed by the work these students were doing? However, as we continued to talk about the experience, we realized that we had fundamentally different understandings of the responsibilities of citizenship and of what it means to be an engaged citizen. Knowing that our perceptions of citizenship are shaped starting at an early age, I began to wonder whether young people in Germany would share the perceptions of my colleague. Ultimately, that experience led to this research project, which explores cultural differences in the connotations associated with the term "engaged citizen" among young people.

Citizenship has been defined in a variety of ways. According to Leydet[3], citizenship can be defined in three different ways: 1) as a legal status, a set of rights and responsibilities that is conferred by a nation or state, 2) as political agency, or 3) as identification with a particular political community. More recently, scholars such as Rosaldo[4] have introduced yet another aspect of citizenship: cultural citizenship. According to Rosaldo, "cultural citizenship refers to the right to be different and to belong in a participatory democratic sense." An important theme running through all of these conceptualizations of citizenship is the active participation of the individual citizen. Indeed, engagement is seen as fundamental to citizenship in a participatory democracy, as explained by Jansen, Chioncel, and Dekkers[5] who argue that "being involved in social practices is conditional for learning how to participate."

The importance of creating an engaged citizenry is clear, and much of the responsibility for meeting that goal has been placed on educational institutions. Increasingly, schools, colleges and universities are attempting to meet that goal by integrating service-learning and other civic engagement activities into their curricula. A recent poll conducted by the American Association of Colleges and Universities[6] reported that civic engagement is an expected learning outcome in $2 / 3$ of its member institutions.

As educational institutions seek to engage citizens, it is critically important to consider the perspectives of young people. Research shows that attitudes towards citizenship are formed early and "persist into adulthood[8]." Therefore, understanding how young people view citizenship and how those perceptions are communicatively constructed is a logical and necessary step in encouraging young people to become actively involved and in designing educational programs that effectively promote civic engagement. The first research question this study seeks to address is: "According to young people, what does it mean to be an engaged citizen?"

Another important consideration for universities as they seek ways to promote an engaged citizenry is to recognize, as the story shared above illustrates, that there may be cultural differences in the assumptions made about what it means to be a responsible citizen. Tonkin[9] warns of the dangers inherent in failing to recognize cultural differences that may influence the cultural transferability of civic engagement.

There is a limited but growing body of research that explores the underlying cultural frames or world views that may account for differences in civic culture. For example, Kecskes[10,11] applies a cultural frame typology to attitudes towards civic engagement. Kecskes suggests that of the four cultural frames in the typology developed by Thompson, Ellis, and Wildavsky[12], hierarchical, individualistic, fatalistic, and egalitarian, the latter is the one that is traditionally associated with "service-learning" as a preferred form of civic engagement. He suggests that civic engagement might evolve into something quite different within a different cultural frame. As multicultural models of civic engagement are developed, the importance of adapting those models to diverse cultural standpoints becomes salient.

A previous study conducted by Goering and Henderson[13] discovered that Germans and Americans define civic engagement quite differently. American youth define being an engaged citizen as "doing good in the community," "community service," "giving back by helping others," "coming together to do something good in your community" or "helping others by doing good things." German youth, on the other hand, define an engaged citizen as someone who "lives peacefully in community" and is politically active. The German youths' conceptualization of an engaged citizen also included being well-educated, watching the news, staying informed, and "taking care of yourself, because the way I live affects other people."

Indeed, past research suggests that our understandings of citizenship are shaped by culture, and this study seeks to explore those cultural differences in more depth through the use of narrative analytical techniques. Just as it is important to consider the perspectives of young people when designing educational programs that promote civic engagement among youth, there is value in understanding cultural differences in conceptions of citizenship when developing these programs. Specifically, this study seeks to answer the following research question: In what ways do the stories of engagement told by youth from different cultures differ from one another?

\section{Materials and Methods}

\subsection{Data Collection}

Arguably one of the best ways to study civic engagement among youth is to talk with young people about their own experiences. Consequently, the method selected for this study was thematic content analysis of focus group interviews with youth between the ages of 11 and 19 (average age $=16.2$ ) in the United States and in Germany. Germany was selected as the country to contrast with the United States because of the extensive literature on 
civic-mindedness within that culture by other researchers such as Janmaat[14] or Silbereisen, Tomasik, and Grümer[15] and because of access of the author.

Twenty-five youth in a major metropolitan area in the Midwest of the US participated in four focus groups. The participants were recruited through community programs for at-risk youth. In Germany, 21 youth participated in three focus group interviews. The German participants were recruited from upper-level English classes in a Gesamtschule in a mid-sized city in central Germany. At the request of school officials, the German focus groups were conducted in English. Each focus group lasted between 75 and 120 minutes, and the following questions were used to guide the focus group discussions: What does it mean to be civic-minded? How do you define civic engagement? Tell me of a time when you had to decide to either participate or not participate in a civic engagement activity. What decision did you make and what factors influenced your decision? What institutions (i.e., schools, religious institutions) influence and/or cultivate civic-mindedness and civic engagement among youth? What degree of influence do your peers have on whether or not you become civically engaged? What messages do you receive that dissuade you from becoming civically engaged? What obstacles do you encounter as it relates to your participating in a civic event? What would you suggest as a way to promote the value of civic-mindedness and civic engagement among youth? Institutional Review Board (IRB) approval was requested and received for the project from the IRB at the author's home university.

\subsection{Data Analysis}

Because the focus of this study was on the stories of engaged citizenship that were shared during the focus groups, the first step in the data analysis process was to identify the sections of text that qualified as narrative. Content was considered to be narrative if it told a recognizable story about an action the storyteller perceived to be an act of engaged citizenship. Once the narrative units were gleaned from the focus group transcripts, the stories were analyzed using thematic content analytical methods, as described by Bereleson[16]. The elements of the grammar of story identified by Stein and Glenn[17] provided the primary categories for the data analysis. For each narrative, relevant themes related to each of the story elements were coded using a "constant comparison technique[18]," indexing common and divergent themes related to each category. The constant comparative technique is an inductive analytical approach, in which themes emerge from the data rather than being superimposed on the data. The themes emerging in the first narrative provided the framework for the analysis of subsequent narratives. As additional narratives were analyzed, findings were constantly compared to the previously identified themes, and the thematic categories related to each topic area were fine-tuned and refined. This approach was appropriate because the goal of the research is to give voice to young people and this methodology was seen as the most effective way to do that.

\section{Results}

A total of forty-five narratives were identified in the focus group transcripts, twenty in the focus groups with German youth, and twenty-five in the focus groups with American youth. This results section is organized according to the elements of story identified by Stein and Glenn. The major themes related to each element are summarized, focusing specifically on the communicative construction of perceptions of engaged citizenship.

\subsection{Setting}

According to Stein \& Glenn, setting is where the action of the story takes place. Nine setting categories were observed in the data (see Table 1). The most common setting for reported stories of engagement was a social service organization, such as a food pantry, a nursing home, or a homeless shelter. Nearly one-quarter of the stories shared by the youth were set in an organization such as this. The second most common setting, appearing in 8 of the 45 narratives, was the storyteller's immediate community or neighborhood, and the third most common setting was a religious institution, which was the setting for 6 of the stories.

When one compares the settings of the stories across the two populations (German vs. US), some intriguing differences emerge. Most noticeable, perhaps, are those settings that are relatively popular in one population but completely absent from the narratives generated by the youth in the other culture. The American youth, for example, situate a considerable amount of their engagement activity in the church, in church-sponsored activities, or within their immediate neighborhood. For example, one story shared by an American female was of a mission trip she was encouraged to go on through and with her church. Another example is a story shared by an American female of an event organized by her church to "take guns and weapons out of the community." The story teller explains: "Probably everyone in here has lost someone to gun violence... I would want to be involved with this event." None of the narratives from the German youth had the church as the setting, and none of them were directly situated within the storyteller's neighborhood.

Conversely, the most popular setting for the German narratives was political protest, a setting that is completely absent in the American narratives. These political activities will be discussed in more depth in a later section. 
Table 1. Setting in Civic Engagement Narratives

\begin{tabular}{|c|c|c|c|c|c|c|}
\hline & Combined & Total & German & Youth & US & Youth \\
\hline Scene & $\mathbf{n}$ & $\mathbf{\%}$ & $\mathbf{n}$ & $\mathbf{\%}$ & $\mathbf{n}$ & $\mathbf{\%}$ \\
\hline Social Service organization & 10 & $22 \%$ & 4 & $20 \%$ & 6 & $24 \%$ \\
\hline Community or neighborhood & 8 & $18 \%$ & 0 & -- & 8 & $32 \%$ \\
\hline Church & 6 & $13 \%$ & 0 & -- & 6 & $24 \%$ \\
\hline Organized Protest & 5 & $11 \%$ & 5 & $25 \%$ & 0 & -- \\
\hline Social Network & 5 & $11 \%$ & 3 & $15 \%$ & 2 & $8 \%$ \\
\hline Other & 4 & $9 \%$ & 3 & $15 \%$ & 1 & $4 \%$ \\
\hline Sports Club & 3 & $7 \%$ & 3 & $15 \%$ & 0 & -- \\
\hline Political Organization & 2 & $4 \%$ & 2 & $10 \%$ & 0 & -- \\
\hline School & 2 & $4 \%$ & 0 & -- & 2 & $8 \%$ \\
\hline Totals & 45 & & 20 & & 25 & \\
\hline
\end{tabular}

Table 2. Initiating Events in Civic Engagement Narratives

\begin{tabular}{|c|c|c|c|c|c|c|}
\hline & Combined & Totals & German & Youth & US & Youth \\
\hline Initiated by: & $\mathbf{n}$ & $\mathbf{\%}$ & $\mathbf{n}$ & $\mathbf{\%}$ & $\mathbf{n}$ & $\%$ \\
\hline Friend or family member & 16 & $48 \%$ & 5 & $41 \%$ & 11 & $53 \%$ \\
\hline Self & 7 & $21 \%$ & 3 & $25 \%$ & 4 & $19 \%$ \\
\hline School official/teacher & 3 & $9 \%$ & 0 & -- & 3 & $14 \%$ \\
\hline $\begin{array}{c}\text { Church leader/youth group } \\
\text { sponsor }\end{array}$ & 2 & $6 \%$ & 0 & -- & 2 & $9 \%$ \\
\hline $\begin{array}{c}\text { Club advisors/ } \\
\text { leaders/members }\end{array}$ & 2 & $6 \%$ & 2 & $17 \%$ & 0 & -- \\
\hline Celebrity & 2 & $6 \%$ & 2 & $17 \%$ & 0 & -- \\
\hline $\begin{array}{c}\text { Representative of the judicial } \\
\text { system }\end{array}$ & 1 & $1 \%$ & 0 & -- & 1 & $5 \%$ \\
\hline Totals & $33 *$ & & $12 *$ & $100 \%$ & $21 *$ & $100 \%$ \\
\hline
\end{tabular}

\subsection{Initiating Event}

According to Stein and Glenn, the initiating event is the action that sets up the story. Within the context of these engaged citizen narratives, the initiating event was operationalized as the incident, person, or message that served as the catalyst for the specific act of engagement. The initiating events fell into seven categories (See Table 2), with friends and families being the most frequent initiators, instigating the action in 16 of 33 stories. One German respondent, for example, shared a story of working in a food pantry. "My mom told me about it, and I wanted to try it," the respondent explained. The initiating event with the second highest frequency was "Self." The narratives in this category were stories in which the storyteller decided on his or her own to participate in an act of engagement.

As with Setting, some interesting differences can be seen when comparing the narratives shared by the German and American youth. "Friends and family" and "Self" were the top two in both, but that is where the similarity ends. In fact, the remaining "Initiating Event" categories were evident in only one culture or the other. For the American youth, acts of engagement were frequently initiated through their schools or churches. For many of the American youth interviewed in this study, educational institutions provided opportunities which framed and contextualized engagement as a way for them to personally excel while also contributing to the community good. For example, some youth reported that their schools required them to perform ten hours of community service, and they listed these activities as examples of "civic engagement." In these particular situations, youth chose from a variety of available activities including cleaning up parks, planting trees, or reading books to kindergartners and first graders. Interestingly, the students who received school credit for some of their civic engagement activities were more likely to list additional similar acts in which they have participated without being required to do so. For example, one respondent who was required to do community service through her school also reported writing grants on her own time as a way to ensure that after school youth programs were created and maintained within her community. She explained that she did it so that young people "don't get in trouble or go to jail, do drugs or be places they're not supposed to be, act out and do things they're not supposed to do."

German youth did not identify churches or schools as catalysts for engagement in their stories. Instead, in the German narratives, sports clubs were more likely to be the 
initiator of engagement activities. Students shared stories of teaching children to play soccer or coaching youngsters learning to dive as their examples of engagement.

Note the role institutional affiliations play in instigating acts of engagement. In many of the stories, one gets the feeling that without institutional membership, whether that is a school, a church, or a sports club, the opportunities identified by the youth as engaged citizenship would likely not have been present in their lives.

\subsection{Internal Response}

According to Stein and Glenn, the third element of narrative is the "internal response", which is the protagonist's reaction to the "initiating event." Because the narratives elicited in the focus groups were stories of acts of engagement, the behavioral reaction in each case was to do the recommended act. However, the cognitive internal reaction, or the reason provided for doing so, varied considerably (See Table 3). The most common internal reaction observed in these narratives was a "sense of obligation." In the majority of these stories, the storyteller explicitly or implicitly communicated that the reason the protagonist participated in the act was because he or she felt obligated to do so. This was a significantly more common aspect of the German narratives than of the American, evident in $61 \%$ of the German stories and only $13 \%$ of the US stories.

Two themes are evident in the "sense of obligation" category, representing two different loci of obligation. In some of the narratives, the feeling of obligation that motivated the act of engagement is a more general sense of what the responsibilities and duties of a citizen are. This can be seen in the following statements drawn from German narratives: "I think it's very important. It's our responsibility. If we don't do it [participate in political processes], we can't change" or "Taking care of myself is part of being a good citizen-being responsible. The way I live affects other people." These statements imply that the obligation that motivates action is to an understanding of what it means to be a good citizen. A German might describe these behaviors as Selbstverständlich—something that goes without saying.

In other stories, the sense of obligation appears to be directed towards the organization or club that hosted the act. This is illustrated in the following story shared by a German student: "I am in a diving club. I'm working with the children who have never dived before. I volunteer because I want to give the club this work back." This sentiment is implied in another story shared by another German: "I volunteer with a football club. I train small children. I play in this sports club, and this is a program they have for small children." In this story, the sense of obligation the storyteller feels for the club he is a part of is communicated in a way that implies it almost goes without saying: If I am a part of this club, and this club runs this program, then I owe it to my club to participate.
The sense of obligation communicated in the American stories is slightly but notably different than in the German narratives. The most noticeable difference is that a sense of obligation is not a part of the American narratives as frequently as in the German stories. When it is part of the story, the locus of obligation is slightly different than in the German narratives. In some of the American stories, the obligation is to a particular individual. This can be seen in the narrative where an American youth explains: "I have to do it. I still clean the church. I do it to help my grandma."

The second most common catalyst for engagement is that the action was recommended by a friend or family member. This internal reaction can be clearly seen in the following story shared by an American student: "Our choir goes to nursing homes, and my grandma lives there. If she tells me that there is no one to minister to them then I think this is a priority because my grandma is telling me that there's not been anyone to minister to the nursing home." This internal reaction was more prevalent in the American narratives than in the German, appearing in $33 \%$ of the American stories and only $15 \%$ of the German. Although this internal reaction was less common in the narratives from the German focus groups, two of the stories shared by German youth identified friends or families as the motivating factor behind their engagement. One student, for example, told a story of working at a vacation camp for people with disabilities, explaining, "I have a friend and the mother is a member of this organization, so my friend was doing it and invited me to come along."

While the "friend or family member as catalyst for engagement" theme was evident in some of the German narratives, as mentioned above, it was much more prevalent in the narratives shared by the American youth. Several of the stories shared by the American youth suggest that their acts of engagement are motivated by their parents, but not necessarily by a specific message that motivated the particular act described in their narratives. Rather, the internal reaction is more of a mindset or worldview that has been instilled in them by their parents. This can be seen in the following statements drawn from the American narratives: "It's how you're raised. My dad's in the military and we have done community service in lots of places." "Mother raised me to help others. We have washed cars, picked up trash, helped at the homeless shelter together."

The third most common internal reaction was seeing an immediate need and responding to it. This was the case in 6 of the stories, all of them shared by American youth. One good example is a story shared by a young man who helped a guy whose car was on fire: "I did my best to help him with what objects I had at hand. It's not donating money, but it's still helping. I almost caught myself on fire!" Another student shared a story of mowing a neighbor's lawn as an example of engaged citizenry.

Two conclusions related to this internal reaction category are worth noting. First, acts of engagement that are reactions to immediate needs do not seem to foster a sense of what it means to be an engaged citizen that is likely to 
persist over time. The story about mowing the neighbor's lawn ends with the student concluding: "I will never do it again. The old man never thanked me." Second, it is interesting that this internal reaction is completely absent in the stories shared by German youth, because I'm confident that German youth also mow their neighbors' lawns or would help put out a car that is on fire. The difference may be in whether or not those acts are framed as examples of an "engaged citizen."

While these three internal reactions are the most prevalent in the accounts of engagement shared by the youth in this study, there are other motivators evident in the narratives, as Table 3 suggests. The motivating factor in some of the narratives was receiving a tangible benefit such as extra credit or pay. One story was shared by an American student who had been required to do 20 hours of court-ordered community service. This student's motivation is captured in his observation: "You do it or you pay a fine and do more time."

\subsection{Attempt}

The fourth element in Stein and Glenn's grammar of story is "attempt", which is the action taken by the protagonist. In these narratives, "attempt" was operationalized as the activity in which the protagonist participated - the act that was perceived by the storyteller as an act of engaged citizenship (see Table 4). There are some notable differences in the actions that constitute engagement across the two cultures represented in this sample. Youth from both cultures participate in volunteer activities, but in the US, more of those volunteer activities are coordinated institutionally, through churches and schools, as has been mentioned previously. Volunteer activities include planting trees, cleaning up parks, tutoring, or performing at homes for the elderly.

Many of the narratives told by the German youth involved political activism, a form of civic engagement that was noticeably absent from the American students' responses. The importance of participating in political activism was explained by one student who said, "I think [protesting when you see injustice is important], because if the whole community thinks it's not okay, we need to work against it. We have to do that." Another student added, "When rights and privileges are being taken away, it's important to protest. It's important to protest to protect the things you have." The specific protest activities the German students report having participated in include anti-Nazi protests, strikes, online petitions, boycotts, demonstrations for better education, and demonstrations against fascism. Not all of the examples of political activism were organized collective activities, though. One student talked about her own efforts to raise awareness about vegetarianism as civic engagement. She argued that in and of itself, her decision not to eat meat is an act of protest, noting: "I think it is a protest to refuse to eat meat. Animals are living creatures, so to not eat meat is a kind of protest." She explained further that she chooses not to participate in the violent protests of some animal rights groups, opting instead to "talk with people one on one."

Both Germans and Americans told stories that involved donating, including money for disaster relief, used clothing to charity or canned goods to a local food pantry. An interesting difference between the narratives of the German and American youth is that the donations of the German youth in every case were money, whereas the American youth were more likely to donate non-monetary tangible goods. Also, the stories shared by the American youth were more likely to involve coordination of donations within a community - not just individual donations. For example, one student tells of a food drive that was started at her school, and another describes her efforts to collect Yoplait yogurt lids from her friends and neighbors to raise money for breast cancer research. Implicit in these efforts is the institutional support from schools and churches that characterizes "civic engagement" in the US.

Table 3. Internal Reaction in Civic Engagement Narratives

\begin{tabular}{|c|c|c|c|c|c|c|}
\hline & Combined & Totals & German & Youth & US & Youth \\
\hline Internal Reaction/Motivation & & & $\mathrm{n}$ & $\%$ & $\mathrm{n}$ & $\%$ \\
\hline Sense of obligation & 11 & $30 \%$ & 8 & $61 \%$ & 3 & $13 \%$ \\
\hline Recommended by friend or family & 10 & $27 \%$ & 2 & $15 \%$ & 8 & $33 \%$ \\
\hline Response to immediate need & 6 & $16 \%$ & 0 & -- & 6 & $25 \%$ \\
\hline Received a tangible reward & 3 & $8 \%$ & 1 & $8 \%$ & 2 & $8 \%$ \\
\hline Personally care about the cause & 3 & $8 \%$ & 1 & $8 \%$ & 2 & $8 \%$ \\
\hline Desire to "give back" & 2 & $5 \%$ & 1 & $8 \%$ & 1 & $4 \%$ \\
\hline Court ordered & 1 & $3 \%$ & 0 & -- & 1 & $4 \%$ \\
\hline Nothing better to do & 1 & $3 \%$ & 0 & - & 1 & $4 \%$ \\
\hline
\end{tabular}


Table 4. "Action" in Civic Engagement Narratives

\begin{tabular}{|c|c|c|}
\hline Attempt/Action & German Narratives & US Narratives \\
\hline Volunteering & $\begin{array}{c}\bullet \text { volunteered at summer camp for people with } \\
\text { disabilities } \\
\bullet \text { volunteered at diving club } \\
\bullet \text { taught children to play soccer } \\
\bullet \text { volunteered at food pantry } \\
\bullet \text { provided leadership in an club } \\
\bullet \text { worked in laundry } \\
\end{array}$ & $\begin{array}{l}\bullet \text { cleaned up park/community } \\
\bullet \text { volunteered at homeless shelter } \\
\text { • mentored at community center }\end{array}$ \\
\hline Church-related activities & & $\begin{array}{l}\text {-participated in dance ministry } \\
\text { •went on church mission trips } \\
\bullet \text { cleaned up after disaster } \\
\text { •helped with Vacation Bible School }\end{array}$ \\
\hline School-related activities & & $\begin{array}{c}\text { - participated in school clubs (i.e, ROTC, Student } \\
\text { Council) } \\
\bullet \text { washed cars as fundraiser } \\
\bullet \text { wrote grants } \\
\bullet \text { completed required service learning }\end{array}$ \\
\hline Political Activism & $\begin{array}{l}\bullet \text { participate in political process } \\
\bullet \text { boycotted products } \\
\bullet \text { demonstrated for better education } \\
\bullet \text { spoke out about vegetarianism } \\
\text {-participated in anti-poverty demonstrations } \\
\bullet \text { participated in anti-fascism protests } \\
\text { •protested against animal cruelty } \\
\end{array}$ & \\
\hline Donations & $\begin{array}{l}\bullet \text { donated to disaster relief } \\
\text { - gave money to local charities }\end{array}$ & $\begin{array}{c}\bullet \text { •donated clothes } \\
\bullet \text { donated toys at Christmas } \\
\bullet \text { collected canned food } \\
\bullet \text { collected Yoplait lids for breast cancer research }\end{array}$ \\
\hline Help individual & & $\begin{array}{l}\text { - helped stranger with burning car } \\
\text { •cleaned church with grandmother } \\
\text { •helped uncle on farm } \\
\bullet \text { cleaned aunt's house } \\
\bullet \text { mowed neighbor's yard }\end{array}$ \\
\hline Care for self & $\begin{array}{l}\text { - stay informed about current affairs } \\
\text { • stay healthy }\end{array}$ & \\
\hline
\end{tabular}

\subsection{Consequence/Reaction}

For the purposes of this research, the final two elements of Stein and Glenn's grammar of story, Consequence and Reaction, have been combined into one. According to Stein and Glenn, these elements refer to the results of the protagonist's actions and the protagonist's response to those consequences. In the analysis of these narratives, "consequence and reaction" were operationalized as the moral that is embedded in the narrative, the lesson learned, the "take-away" from the experience. Not all of the narratives had a clear Consequence/Reaction, but Table 5 summarizes the results from those that did.

One theme that was mirrored in the narratives from both student groups was the realization that there are costs associated with being an engaged citizen. One German student concluded his story by emphasizing, "It's hard work!" On the other hand, students from both cultures highlighted the benefits of their engagement activities as well. For example, after sharing the story of her 2 weeks spent volunteering in a summer program for people with disabilities, a German respondent concluded, "It was rewarding. It was satisfying, and it was fun because handicapped people are very thankful when you spend time with them." For one American student, the costs outweighed the benefits in the end. She explains, "Grandma and I fixed breakfast for Sunday School...but I don't do it anymore because I like to sleep in."

A theme related to consequences and reactions that is explicitly expressed in the German stories but not in the American is the conclusion that "we can make a difference." One student concluded his story with the observation that "if we don't act, we can't change. It's very good if we participate because then things will get better." The absence of this theme in the American narratives does not necessarily mean that American youth do not believe they can make a difference. In fact, one might assume that they would not participate in engagement activities if they thought otherwise, but none of these participants explicitly affirmed this in their narratives.

Another reaction theme that is unique to the German stories is the conclusion that sometimes the act by itself is not enough. This can be seen in a narrative about political involvement, with the storyteller adding, "Very often it's easy to say, 'Oh, I'm against it.' And many people do this. They complain. It's also really important to stand for 
something and do something. You can't just be against something; you have to present an alternative."

The "take-away" lessons embedded in the narratives from the American youth that are not included in the stories shared in the German focus groups seem to share an individualist orientation, which is not surprising giving the high level of individualism that is typically associated with American culture. The individualism is seen first in the fact that students assume personal responsibility for their actions, as can be seen in the following narrative: "This is our environment, so I am going to pick it up. Kids are our future, so I am going to be a mentor or write a grant. I ask, 'What can I do for the programs that are not going to be funded this year because [the public schools] say they can't afford it. Of course, I am going to write them a grant, especially if it keeps or gets kids engaged." The implied moral of these stories is that if you don't help solve the problem, no one will. The individual orientation is also seen in the stories that highlight the fact that the storyteller will only participate in acts of civic engagement if he/she gets something out of it. One student included the claim, "Ultimately my responsibility is to myself," in his narrative of engagement, and another shared a story of helping an aunt when the aunt was ill. The student concluded her story, claiming that she would "never do it again, because all her aunt did was complain." Finally, the individual orientation is seen in the fact that a handful of stories told by the American youth highlight the fact that they are more drawn to causes they personally can relate to. One student shared, "I give money at Christmas because I know how hard it is to get presents at Christmas time when you have kids. I am a single parent, a teenager, working and going to school, so I know how hard it is."

A final "consequence/reaction" theme that is evident in several of the stories shared by American youth is the recognition that the youths' attitudes towards engagement have been shaped by their interaction with others. How these interactions can contribute to the creation of a mindset that values engaged citizenry has been established previously in this paper. The following two narratives demonstrate how it can influence decision making related to a particular act of engagement:

"There are five kids in my family and we have family meetings every week. We talk about what we can do to make the community better. I was against picking up trash in the community. Why should we clean up someone else's mess when they are just going to throw trash back on the ground? But my older brothers and sisters they got me into doing what is right. They said, as long as you are doing right than why not clean it up? They might not actually be able to pick it up, they might not be able to bend over, but you can."

An intriguing feature of this story is that discussions about what it means to be a good citizen apparently are a regular part of the discourse within this family. Another interesting aspect of the story's plot is that the protagonist initially resisted participating in the act of engagement, but was persuaded differently by his siblings.

This same pattern is evident in the following narrative; only in this case, the persuading is done by classmates:

"At my school we started a canned food drive. I don't know why I didn't do it but I think why I didn't want to do it was because at the time I wasn't educated about giving people things or if you don't receive anything back from giving people things it's ok you choose to help somebody but we were in class and my classmates helped me understand it would be helpful to give away the cans we are not using to people who need them so they talked me into it. We were in class and we were talking and they said it was a good chance to give back or whatever, give to others who need the cans. So after talking, so yeah, I decided it was a good thing."

This narrative evidences the role of friends and peer groups in communicatively constructing attitudes towards civic-mindedness. While initially this student did not place the same value on the particular act (donating to the canned food drive) as her peers, through peer-to-peer discussion the individual was challenged to rethink the meaning she associated with the act, and ultimately her opinions about the act converged with those of her classmates. Through the group communication process, an act of civic engagement and the values associated with this act actually became cultivated within this individual's value system.

Table 5. Consequences/Reactions in Engaged Citizen Narratives

\begin{tabular}{|c|}
\hline $\begin{array}{c}\text { Consequences/Reactions Embedded in German Narratives } \\
\bullet \text { It is hard work. } \\
\bullet \text { It is rewarding/satisfying. } \\
\bullet \text { We can make a difference. } \\
\bullet \text { Sometimes the single act is not enough }\end{array}$ \\
\hline $\begin{array}{l}\text { Consequences/Reactions Embedded in US Narratives } \\
\text {-There are many ways to demonstrate engagement. } \\
\text { - It is up to me to take an active role in making my community a better } \\
\text { place. } \\
\text {-I have to get something out of it, or I'll stop doing it. } \\
\text { - My engagement is largely shaped by my interactions with other } \\
\text { people. } \\
\bullet \text { There is a cost to being an engaged citizen. } \\
\bullet \text { Causes I can personally relate to are more appealing to me. }\end{array}$ \\
\hline
\end{tabular}

\section{Discussion}

The analysis of these narratives generated by young people in Germany and the United States demonstrate that, indeed, there are cultural differences in understandings of what it means to be an engaged citizen. On the one hand, the American and German youth define civic engagement in a similar manner: a common thread in all of the definitions of civic engagement presented by the young people is that it involves working to meet community needs. However, closer analysis reveals that German and American young people approach the construct of civic engagement from very different conceptual standpoints. To the American youth, "working to meet community needs" means tangibly solving problems (i.e., working at food pantries, tutoring, helping clean up after a disaster), but to the German youth, 
"working to meet community needs" means taking the political actions necessary to ensure that the government meets its obligations to the people. For example, German youth are more likely to engage in protests against poverty or for policies that ensure fee-free access to education for all than they are to participate in projects that provide direct material aid to people in need. This represents a fundamental difference in the conceptualization of civic engagement, a difference that is not inconsistent with existing research on civic involvement within these two countries. A study of political activity and volunteerism conducted as part of the American Democracy Project's Political Engagement Project discovered that young people in the United States are more likely to engage in apolitical community service than in political activities[19]. This stands in stark contrast to the emphasis placed on political activism as civic engagement reported by the German youth in the current study. This difference has implications for the types of intra- and inter-cultural civic engagement programs educational institutions might develop as well as for the particular activities embedded into those programs.

It is interesting to note that while connotations of engaged citizenship differ, the communicative processes through which those understandings are constructed do not seem to vary across cultures. In other words, the communicative processes, the storying, restorying and construction of shared rhetorical visions about what engaged citizenship means, are the same. While the process is the same, there are notable differences in each of the story elements across the two cultures, but what can these similarities and differences teach us about how to engage citizens?

The stories provide compelling evidence of the communicative construction of perceptions of citizenship. They suggest that institutions, such as family, school, or religious institutions, can play a particularly significant role in shaping youths' experiences and expectations related to civic engagement. In the absence of institutional membership, the propensity for future civic engagement appears to be reduced. This highlights the need for educational institutions to continue to play a key role in educating citizens.

The narratives of engagement shared by the focus group participants also suggest that young people often have key individuals who are particularly influential, grandmothers, teachers, parents, or friends, for example. The opinions of these key individuals play an important role in communicatively constructing the value the story teller places on the particular act of engagement. As illustrated in the stories presented in this paper, if the influential person saw the choir's visit to the nursing home or the canned food drive or volunteering at the food pantry as important, the young person did as well. Of course, the opposite can also be true. Some of the narratives shared in these focus groups also describe instances where individuals decided to forego participating in a particular civic engagement activity because their friends were not participating. As schools and universities design programs that promote civic engagement, it is important for them to recognize the need for constructing civic-mindedness within social contexts. Rather than focusing on teaching individuals to become engaged citizens, perhaps the emphasis needs to be placed on the communicative construction of civic-minded worldviews within the larger social context.

Not only do influential persons impact an individual's decision of whether or not to engage in a specific act, at a more fundamental level, they play an important role in shaping understandings of what it means to be engaged and in creating expectations of community responsibility. This is effectively illustrated in the following narrative:

"I got one for you. This happened on Friday before I was heading down to Bloomington. My buddy's girlfriend, she just got her driver's permit so I let her drive my buddy's car to take her and the baby home, but she wrecked the car in the driveway and her brother called the cops on her. What brother would do something like that? But my buddy didn't have insurance so I went inside and went online and put insurance on the car before the cops got there, and it cost me $\$ 2000$ dollars."

When asked, "Why did you do that?" the storyteller stated, "I didn't want her to go to jail and they have helped me out before, I don't have no money right now [sic] but he can drive."

In this narrative one can trace the communicative construction of the storyteller's notions of civic-mindedness. In this story, the peer group plays a significant role in shaping expectations about what a "good citizen" is expected to do. It seems reasonable to assume that if other spheres of discourse, such as schools, churches, or families, do not play an active role in communicatively constructing those expectations, the peer group may play a disproportionately significant role in shaping young peoples' understandings of what it means to be an engaged citizen. While this finding is not surprising, it is important when it comes to designing civic engagement initiatives that will speak to young people.

In conclusion, I would argue that there is value in seeking ways to foster a mindset of engaged citizenship in young people. Acts of engagement need to be more than a school requirement. The mindset of an active and engaged citizen - whatever that may be within a particular cultural context - needs to be instilled in young people as part of the worldview. While this is a challenging goal, it is attainable, as evidenced by one final narrative I wish to leave you with in closing:

"When I'm given an opportunity to be civically engaged I take it. Even when I am hanging out with friends I actually do community service. I remember a time my cousin and I went to the park and there was trash everywhere so we just went around on our own and cleaned up the trash. And if there were little kids there without their parents we like play with them and make sure they don't get hurt. If I'm given the opportunity I'm going to take it—not turn it down."

The findings of this study suggest several findings that 
have implications for how educational institutions go about seeking to foster this sense of civic engagement among young people. First, young people come to the classroom with pre-existing notions about what it means to be a citizen in general and an engaged citizen in particular. Programs designed to teach citizenship should be aware of and build on those prevailing perceptions. Second, what it means to be an engaged citizen takes on meaning in community. Perhaps educational institutions need to focus less on building individual citizens and more on playing role in the construction of community-shared understandings of the roles and responsibilities of a citizen. Finally, citizenship does not mean the same thing across cultures. Consequently, as schools and universities design civic engagement programs, they need to ensure that those programs are consistent with their cultural context. While this study illustrates that cultures can differ considerably in their constructions of "engaged citizenship," it is limited to just two cultures. Further research could expand the analysis to a wider range of cultural and co-cultural contexts.

\section{Acknowledgements}

The author wishes to acknowledge the contributions of Crystal Henderson, who played a primary role in collecting the data from the American participants.

\section{REFERENCES}

[1] E.L. Dey, C.L. Bamhardt, M. Antonaros, M.C. Ott, M.A. Holsapple. Civic Responsibility: What is the Campus Climate for Learning? Association of American Colleges and Universities, Washington, DC, 2009.

[2] M. Nunn. Re-invigorating democratic participation and activating an engaged citizenry. PACE: Philanthropy for Active Civic Engagement, 1-8, 2005, Online Available: http://www.pacefunders.org/pdf/essays/Nunn\%20FINAL.pdf

[3] D. Leydet. Citizenship. The Stanford Encycolpedia of Philosophy. E.N. Zalta, ed. 2011. Online Available: http://plato.stanford.edu/archives/fall2011/entries/citizenship

[4] R. Rosaldo. Cultural citizenship and educational democracy. Cultural Anthropology, Vol. 9, 402-411, 1994.

[5] T. Jansen, N. Chioncel, H. Dekkers. Social cohesion and integration: learning active citizenship. British Journal of Sociology of Education, Vo. 27, 189-205, 2006.

[6] American Association of State Colleges and Universities.
(2011). American Democracy Project: Political Engagement Project (PEP). Online Available: http://www.aascu.org/progr ams/adp/engagement.htm.

[7] P. Gurstein, C. Lovato, S. Ross. Youth participation in planning: Strategies for social action. Canadian Journal of Urban Research, Vol. 12, 249-274. 2003. Habits from home, lessons from school: Influences on youth civic engagement. Social Education, Vol. 67,

[8] M.W. Andolina, K. Jenkins, C. Zukin, S. Keeter. Habits from home, lessons from school: Influences on youth civic engagement. PS: Political Science \& Politics, Vol. 36, 275-280, 2003.

[9] H. Tonkin. Service-Learning Across Cultures: Promise and Achievement, International Partnership for Service-Learning and Leadership, New York, 2004.

[10] K. Kecskes. Behind the rhetoric: Applying a cultural theory lens to community-campus partnership development. Michigan Journal of Community Service-Learning, Spring, $5-14,2006$.

[11] K. Kecskes, A. Elshimi. Arab World Perceptions of Civic Engagement, International Association for Research on Service-Learning and Community Engagement Conference, Indianapolis, Indiana, 2010.

[12] M. Thompson, R. Ellis, A. Wildavsky. Cultural Theory, Westview Press, Boulder, Colorado, 1990.

[13] E.M. Goering, C. Henderson. Civic engagement in/action: A cross-cultural comparison of youth involvement. Understanding Service Learning and Community Engagement: Crossing Boundaries through Research, J.A. Hatcher, R.G. Bringle, eds., Information Age Publishing, Charlotte, North Carolina, 73-99, 2011.

[14] J.G. Janmaat. Civic culture in Western and Eastern Europe. AES, Vol. 47, 363-393, 2006.

[15] R.K. Silbereisen, M.J. Tomasik, S. Grümer. Soziodemografische und psychologische korrelate des bürgerschaftlichen engagements anfang 2000 in Deutschland. Individuum und Sozialer Wander, R.K. Silbereisen, M. Pinquart, eds., Juventa, Weinheim Germany, 1970227, 2008.

[16] B. Berelson. Content Analysis in Communication Research, Free Press, Glencoe, Illinois, 1971.

[17] N.L. Stein, C.G. Glenn. An analysis of story comprehension in elementary school children. Discourse Processing: Multidisciplinary Perspectives, R. Freedle, ed., Ablex, Norwood, New Jersey, 1979.

[18] B.G. Glaser, A.L. Strauss. The Discovery of Grounded Theory: Strategies for Qualitative Research, Aldine de Gruyter, New York, 1967.

[19] A. Colby. The place of political learning in college. Peer Review, Vol. 10, 4-8, 2008. 